\title{
Arborização viária urbana: espécies de pequeno porte com potencial de uso
}

\section{RESUMO}

A escolha de espécies apropriadas é um dos pontos mais importantes para os profissionais que trabalham com arborização viária urbana. Com esse objetivo desenvolveu-se um estudo no Arboreto do Instituto Agronômico de Campinas, onde foram observadas a morfologia e a fenologia de 22 espécies no período de outubro de 2000 a outubro de 2002, num total de 66 indivíduos que apresentavam tronco sem espinhos e copas arredondadas ou ovaladas. As fenofases analisadas foram floração, frutificação, brotação e abscisão foliar. A maioria apresentou floração longa (mais de quatro meses) com flores vistosas no período primavera-verão. Cordia sebestena, Kielmeyera excelsa, Saraca indica, Lonchocarpus filipes, Metternichia princeps estão entre as que apresentaram grande potencial, por serem as que mais se aproximaram ao padrão desejado para a arborização viária urbana.

Palavras-chave: árvores ornamentais, ecologia urbana.

\section{ABSTRACT \\ Urban trees: species of small size, with potential use}

The selection of appropriate arboreal species is one of the most important points for professionals who work with urban trees. With this purpose, a study was developed at the Instituto Agronômico arboretum located in Campinas, São Paulo State, where the morphology and fenology of 22 species were observed from October 2000 to October 2002 in a total of 66 individuals that presented no thorn on their stems and rounded or ovate tops. The flowering, fruiting, leaf production and leaf abscision were the phenophases observed. The majority presented long flowering (more than four months), with showy flowers in the spring-summer period. Cordia sebestena, Kielmeyera excelsa, Saraca indica, Lonchocarpus filipes and Metternichia princeps were among the species that presented great potential for being closer to the desired pattern for urban forestry.

Key words: ornamental trees, urban ecology

\section{INTRODUÇÃO}

A arborização urbana é tida como a relação entre ambiente arbóreo, estruturas e pessoas, envolvendo a cidade toda (GREY, 1996), tanto ruas e avenidas como praças e jardins. Já a arborização viária urbana é o cultivo de árvores ao longo de ruas e avenidas.

A arborização urbana interfere na vida das pessoas de maneira direta, tanto física como psicologicamente. Na parte física, a arborização não se restringe a melhorar a estética de uma cidade, mas contribui, também, por deixar o microclima agradável, diminuir os ruídos dos carros, ordenar os espaços físicos, valorizando o imóvel e envolvendo a comunidade (LIMA, 1993). No plano psicológico, ajuda o ser humano ao mitigar a probabilidade de estresse.

Em decorrência do crescimento desordenado das cidades e da falta de planejamento, geralmente a arborização viária é prejudicada, causando sérios problemas para a comunidade, como o uso de espécies inadequadas,

\footnotetext{
${ }^{1}$ Engenheira Agrônoma, Estagiária, Centro APTA Horticultura/IAC, Caixa Postal 28, 13001-970 Campinas (SP). E-mail: luz.ferreira@zipmail.com.br

${ }^{2}$ Centro APTA de Horticultura/IAC. E-mail: matthes@iac.sp.gov.br
} 
e provocando problemas em relação aos equipamentos urbanos, como fiação aérea e subterrânea, redes, calçadas, muros, água, esgoto etc. (PALERMO JR., 1987; MILANO, 1996; NUNES, 1996).

Atualmente há falta de estudos sobre o comportamento de espécies para serem utilizadas na arborização e a área que mais recente é a arborização viária. Pesquisas sobre o sistema radicular, hábito e forma de crescimento, tipo de copa e fenologia (IRGANG, 1985) são essenciais para a indicação de espécies para tal propósito.

Segundo KELLER (1994), o tipo de copa está relacionado com o modelo arquitetônico de cada árvore e, para a sua identificação, é necessário observar se o crescimento é monopodial ou simpodial, e, nos modelos de ramificação, se ortotrópicos ou plagiotrópicos. O mesmo autor ressalta que esses modelos são difíceis de serem avaliados em árvores mais velhas, sendo recomendados em árvores jovens, considerando suas primeiras inflorescências. De acordo com HALLÉ et al. (1978), esses modelos se referem ao plano de crescimento da árvore, que não pode ser confundido com o hábito de crescimento, já que esse expressa a forma do organismo (herbáceas, arbustos ou árvores). Recomenda-se, segundo a COMPANHIA ENERGÉTICA DE SÃO PAULO - CESP (1988), que a copa das árvores seja bem formada, com altura de até sete metros na fase adulta, de maneira que não interfira na fiação elétrica e telefônica, nem na passagem de pedestres. FISCHER (1985) considera espécies de copa arredondada e ovalada ideais para arborização viária, pois evitam, também, problemas com as redes elétrica e telefônica. $\mathrm{Na}$ copa arredondada existem ramos ortotrópicos que crescem eretos (HALLÉ et al., 1978) e com ramificação simpodial, ou seja, crescimento dos ramos superiores e brotos laterais (STRASBURGER, 1988), enquanto que na copa ovalada prevalecem os ramos plagiotrópicos, que são quase horizontais com simetria dorsiventral (HALLÉ et al. 1978) e dificilmente se adaptarão em espaços pequenos (SEITZ, 1990). O modelo arquitetônico de cada espécie deve ser considerado para garantir a sua vitalidade quando houver podas (SEITZ, 1990).

A poda é uma atividade que, quando mal executada, pode prejudicar a árvore, ocasionando extensas necroses de tronco e colo (SANCHOTENE, 1990) ou apodrecimento do lenho (SANTIAGO, 1990), comprometendo sua forma peculiar e seu crescimento próprio. A poda é recomendada no caso de formação da muda nas condições de viveiro e para evitar a perda total da árvore, quando danificada por pragas (BIONDI, 1987; NUNES, 1996).
A altura ideal da árvore de pequeno porte não está definida e ainda provoca controvérsias entre diversos autores. PALERMO JR. (1987) recomenda sob fiação somente espécies de pequeno porte com altura máxima de quatro metros, enquanto SOUZA (1994) admite de cinco a sete metros. Há um limite de altura de espécies de pequeno porte recomendado pelo primeiro autor, mas considerado muito baixa; o segundo autor fornece uma medida mais adequada. A Companhia Elétrica de São Paulo - CESP (1988) adota até sete metros para uma altura da fiação de nove metros, o que pode ser considerado como ideal. É necessário estabelecer uma relação harmoniosa entre fiação e arborização viária em termos econômicos e práticos.

Os estudos sobre fenologia têm grande valor na análise da organização biológica das comunidades e ecossistemas; no Brasil, nos ambientes tropicais, os trabalhos que mais se destacaram foram os realizados por Veloso (1945, 1946) e Veloso \& Klein (1957), respectivamente, para Teresópolis, Ilhéus e Brusque e o de Araújo (1970) para Manaus, citados por MATTHES, 1980. Nos últimos 25 anos, $\mathrm{o}$ interesse pelo assunto foi resgatado, comprovado pelo maior número de publicações: MORELLATO et al. (1989); ALENCAR (1990); MORELLATO \& LEITÃO FILHO (1990); MORELLATO et al. (1990); ALENCAR (1994); MACHADO et al. (1997); FERRAZ et al. (1999); MORELLATO et al. (2000); TALORA \& MORELLATO (2000); GRIZ \& MACHADO (2001); MIKICH \& SILVA (2001); BENCKE \& MORRELLATO (2002a e 2002b); FUNCH et al. (2002); d'EÇA-NEVES \& MORELLATO (2004), entre outras.

Para as espécies arbóreas e arbustivas utilizadas na arborização viária urbana, portanto sob cultivo e normalmente fora de suas regiões de ocorrência, os dados sobre a fenologia são mais escassos. A maioria das publicações existentes é citação dos poucos trabalhos realizados e com o agravante de não mencionar a fonte e generalizar as informações para todo o país. Entre os trabalhos publicados pode-se citar os de SOUZA (1973) e SANTIAGO (1980).

Desse modo, procurou-se estudar a morfologia e a fenologia de algumas espécies arbóreas de pequeno porte e arbustos cultivados no Instituto Agronômico de Campinas, SP.

\section{MATERIAL E MÉTODOS}

Os dados meteorológicos referentes ao período de 2000 a 2002 foram obtidos no posto de primeira classe $\left(22^{0} 55^{\prime} \mathrm{S}\right.$ e $47^{\circ} 05^{\prime} \mathrm{W}$ e 669 metros de altitude), situado no Centro Experimental Central (CEC) do Instituto Agronômico (IAC), Campinas, SP, localizado na Av. Theodureto 
de Almeida Camargo, 1500, e as informações para a confecção do gráfico de balanço hídrico, segundo o método de Thornthwaite-Matter (1955, apud Ortolani et al., 1970), foram fornecidos pelo Centro de Pesquisa e Desenvolvimento de Ecofisiologia e Biofísica, também do IAC.

O clima da região é do tipo Cwa (KÖPPEN, 1948) e é definido como tropical de altitude com inverno seco e verão quente e chuvoso. As temperaturas médias mensais na estação quente (outubro-março) estão entre 20 e $25^{\circ} \mathrm{C}$, e na estação fria (abril-agosto), entre 17 e $20^{\circ} \mathrm{C}$, com média anual de $20,6^{\circ} \mathrm{C}$. A partir desses dados, calcularam-se o balanço hídrico dos dados climáticos e a temperatura média no período de 2000 a 2002.

As espécies, de pequeno porte e de arbustos, nativas e exóticas, foram observadas no Arboreto Monjolinho situado no CEC, numa área de aproximadamente 80 hectares, sendo que a maioria possui dados de procedência e data de plantio. O número de indivíduos por espécie é muito variado e é comum encontrá-las com poucos exemplares.

A escolha das espécies em campo foi baseada em atributos discutidos por diversos autores (SANTIAGO, 1980; FISCHER, 1985; WINTERS, 1991; RIBEIRO et al., 1992; LIMA, 1993; SOUZA, 1994; BIONDI, 1996), que definiram o padrão desejado para a arborização viária, relacionando o conhecimento das espécies mais compatíveis, com as limitações físicas existentes, como edificações, largura das calçadas e fiações.

As características morfológicas (Tabela 1) dos indivíduos foram analisadas baseando-se nos seguintes registros: idade, altura, diâmetro na altura do peito (DAP) e altura da primeira bifurcação (BIF), tipo de copa, classificado segundo HICKEY \& KING (2000), e origem. Quando as ramificações ocorrem desde a base do caule, abaixo do DAP, o diâmetro resultou da soma das medidas dos vários fustes.

As observações fenológicas (Tabela 2) foram mensais, realizadas em 22 espécies, em dois a três indivíduos por espécie, no período de outubro de 2000 a outubro de 2002, concordando com FRANKIE et al. (1974), que recomendam de dois a cinco indivíduos por espécie para os estudos de fenologia, em função de sua variação intrínseca.

Foram estudadas as fenofases floração, frutificação, brotação e abscisão foliar. Para a floração foram consideradas desde o surgimento do botão floral, a abertura da flor, até o final do período de floração. Classificou-se o período de floração como longa (mais de quatro meses), média (de dois a três meses) e curta (semanas até um mês). A frutificação abrangeu o período desde a formação do fruto até a sua queda; na brotação foram analisadas as folhas jovens e maduras e sua abscisão, considerando as espécies como decíduas, semidecíduas ou perenifólias.

\section{RESULTADOS E DISCUSSÃO}

O balanço hídrico referente aos anos de 2000 a 2002 mostrou que nos meses de janeiro e novembro de 2000 e fevereiro e outubro de 2001 a precipitação foi a maior registrada na região durante o período de observação. O período de baixa precipitação ocorreu ao longo dos meses de abril a junho de 2000, e junho a julho de 2001 e 2002 (Figura 1).

As temperaturas médias mais elevadas ocorreram, de um modo geral, durante os meses de janeiro a abril e de outubro a dezembro, sendo o mês de julho o de mais baixas. Geralmente o período de temperaturas médias mais baixas ocorre entre os meses de maio e agosto. Entretanto, observaram-se variações: em 2002 a temperatura média foi mais alta no mês de agosto, fato não observado em 2000 e 2001. (Figura 1)

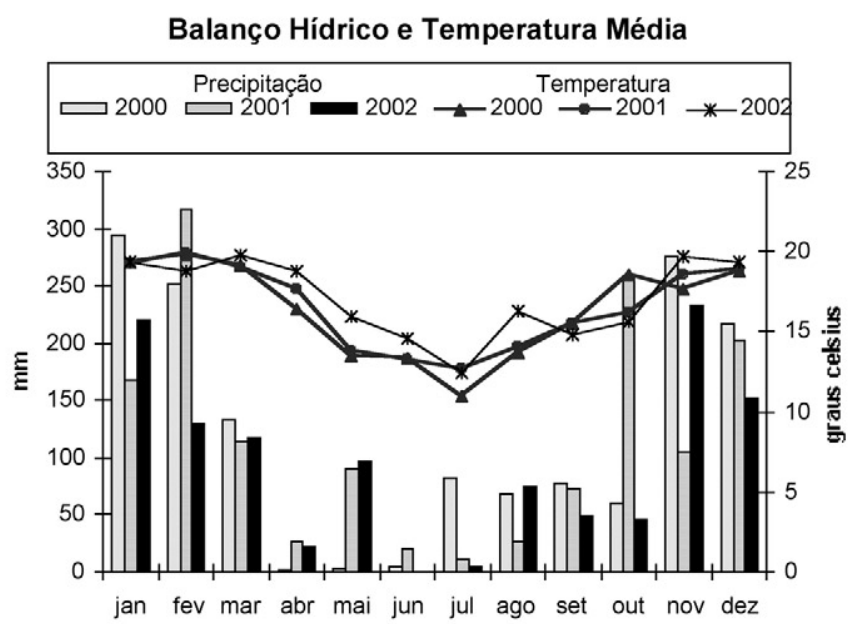

Figura1. Balanço hídrico e temperatura média para os anos de 2000, 2001 e 2002. Dados registrados pela estação meteorológica do Instituto Agronômico de Campinas $\left(22^{\circ} 54^{\prime} \mathrm{S} 47^{\circ} 05^{\prime} \mathrm{W}\right)$.

Parte dos atributos morfológicos para a arborizacao urbana, discutidos por diversos autores mencionados anteriormente, foram observados nas 22 espécies estudadas e esta relacionada na tabela 1 . De acordo com os dados obtidos, verifica-se que a maioria dos indivíduos possui mais de cinco anos de cultivo e que suas medidas de altura, de diâmetro na altura do peito (DAP) e de altura da primeira bifurcação (BIF), variaram bastante. Entretanto, dentre essas espécies, foi possivel encontrar, salvo algumas exceções, espécies com indivíduos com medidas satisfatórias, para serem considerados propícios para a arborizacao urbana. 


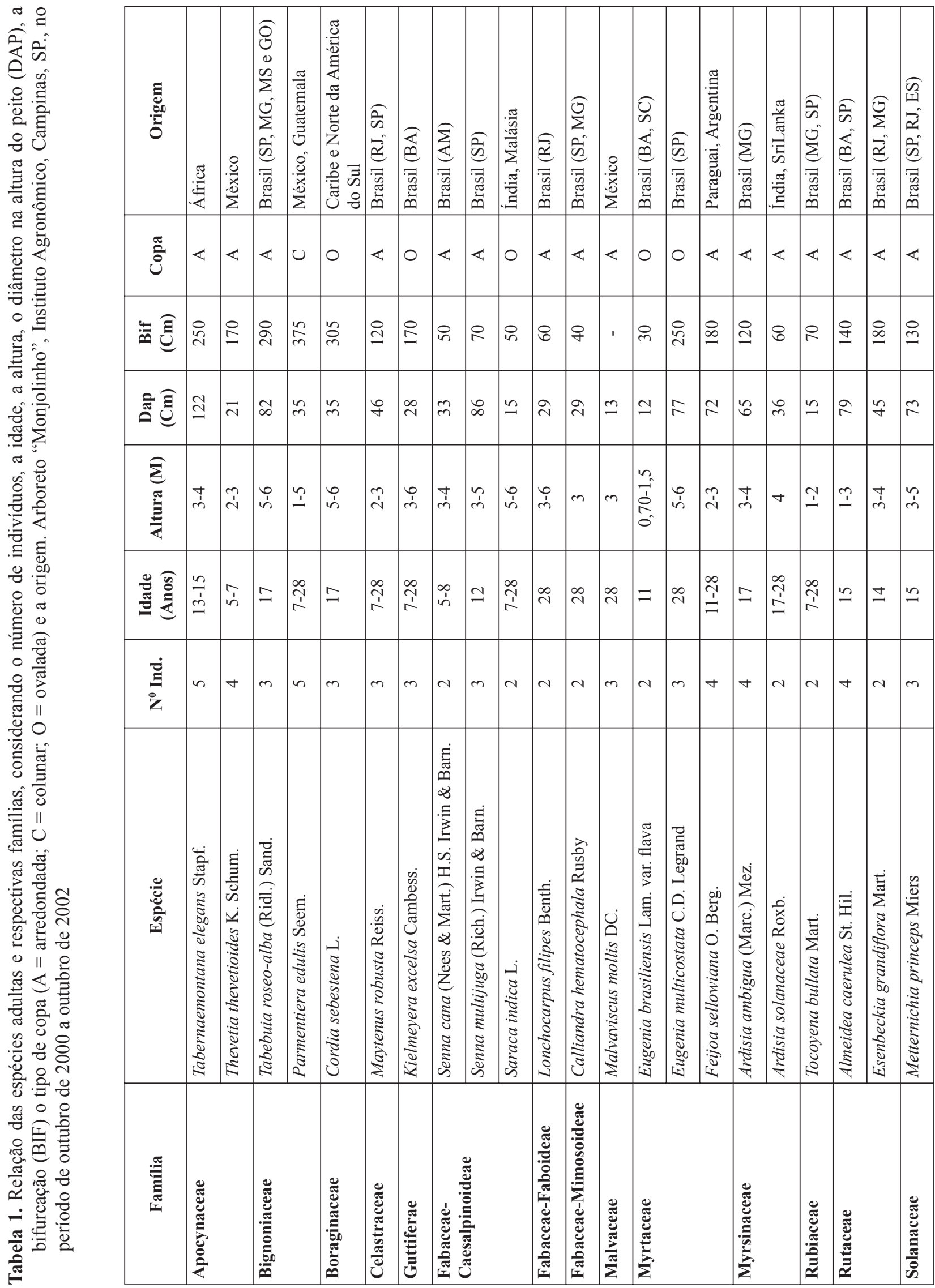




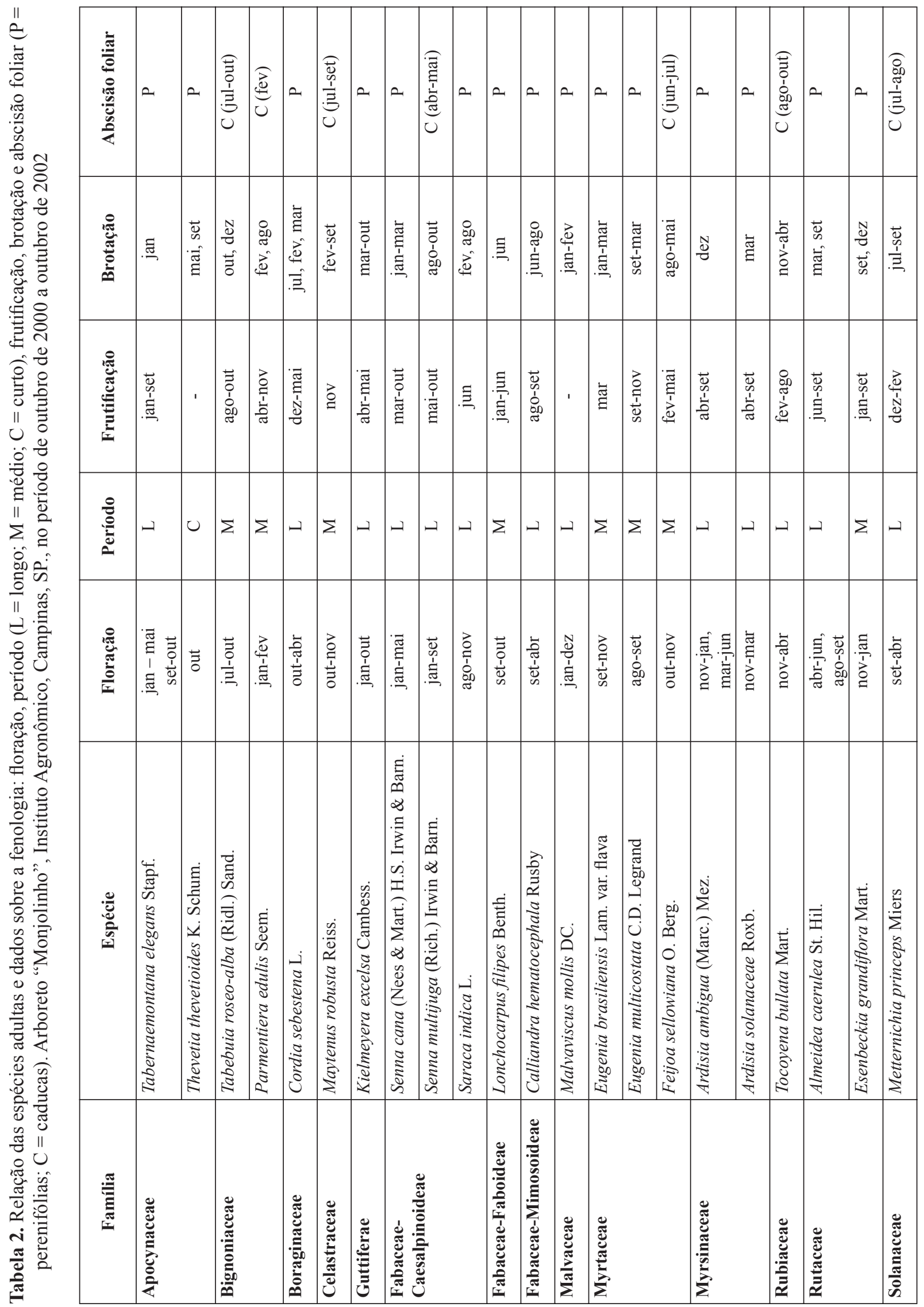


Alguns indivíduos apresentaram brotações abaixo do DAP em função de ser uma característica da espécie e, nesse caso, são considerados como arbustivos; noutros, a brotação foi ocasionada por danos físicos nas plantas, provocados por implementos agrícolas por ocasião da limpeza do terreno. Espécies arbustivas são passíveis de serem utilizadas na arborização viária, fazendo-se a poda das brotações na base e deixando-se somente uma, que deverá ser conduzida até a altura desejada para a formação da copa (SOARES, 1998). Um exemplo bastante comum desse processo é realizado em Lagerstroemia speciosa e Chloroleucon tortum. Esse tipo de ramificação ocorreu em Tabernaemontana elegans, Senna cana, Lonchocarpus filipes, Calliandra hematocephala, Malvaviscus mollis, Feijoa sellowiana, Almeidea caerulea, Esenbeckia grandiflora e Metternichia princeps.

Plantas que apresentam espinhos e/ou acúleos devem ser evitadas na arborização urbana; entretanto, algumas espécies podem ou não apresentar essa característica na fase juvenil e, nesse caso, faz-se a seleção eliminando-se as indesejadas; tal procedimento, por exemplo, pode ser utilizado satisfatoriamente com o Chloroleucon tortum.

Verificou-se, também, que a maioria das copas apresentava a forma arredondada, sendo seguidas pelas ovaladas. Essas, como nunca foram podadas, representavam as suas formas reais, que, segundo FISCHER (1985), são ideais para a arborização urbana.

A Tabela 2 apresenta a relação das espécies com respectivas épocas de floração, frutificação, brotação e abscisão foliar. As espécies que tiveram floração longa com flores vistosas foram: Cordia sebestena, Kielmeyera excelsa, Calliandra hematocephala, Malvaviscus mollis, Tocoyena bullata e Metternichia princeps. Outras, ainda, floresceram em dois períodos do ano, como Tabernaemontana elegans, Ardisia ambigua e Almeidea caerulea.

Segundo LIMA (1993), as espécies utilizadas na arborização viária devem apresentar flores grandes e vistosas; entretanto, WINTERS (1991) e RIBEIRO et al. (1992) sugerem que as flores pequenas sejam as mais adequadas, porque proporcionam menos sujeira nas ruas e calçadas.

Um dos problemas da arborização viária, que se observa, é o entupimento de bueiros e calhas, alguns autores sugerem que as espécies devam ter folhas pequenas e porte pequeno para contornar essa situação (RIBEIRO et al., 1992).

O período de florescimento e o de surgimento de novas folhas ocorreram no início e durante os meses de maiores índices pluviométricos, para a maioria das espécies estudadas, e a frutificação foi mais evidente no final do período chuvoso.

Conforme a necessidade da intensidade de luz, pode-se utilizar espécies perenifólias, decíduas ou semidecíduas, dependendo da situação. As perenifólias podem causar sombreamento excessivo em locais com pouca incidência solar (RIBEIRO et al., 1992; FISCHER, 1985). Para esse caso, existem espécies que apresentam abscisão foliar em determinada época do ano (Tabela 2).

MATTHES (1980), estudando uma comunidade arbórea florestal, localizada também em Campinas (SP), concluiu que espécies que produzem sementes dispersas pelo vento produzem frutos maduros e apresentam maior abscisão foliar no período mais seco, a fim de facilitar a dispersão; exemplos dessas síndromes são as espécies de Tabebuia, aqui representada por Tabebuia roseo-alba. $\mathrm{O}$ mesmo autor observou que as espécies que produzem frutos ou sementes carnosos são dispersas por animais e, geralmente, frutificam no período chuvoso e não perdem as folhas de maneira conspícua; verificou-se esse comportamento em Eugenia multicostata, Eugenia brasiliensis e Cordia sebestena. Também verificou que espécies que apresentam a autocoria podem posicionar seus frutos fora da copa e, nesse caso, não há a necessidade de serem caducifólias. Almeidea caerulea e Esenbeckia grandiflora mostraram esse procedimento. Ressalta-se que essa conduta é mais evidente para espécies arbóreas que coevoluiram com a fauna e que estão sob as mesmas condições de chuva, temperatura e vento durante o processo de evolução.

Quando o estudo fenológico é realizado em plantas cultivadas fora de suas regiões de ocorrência, o comportamento das fenofases, entre si e em relação à época do ano, geralmente muda muito, o que vem justificar a necessidade dessas observações.

SANCHOTENE (1985 e 1990) defende o uso de árvores nativas frutíferas como sendo importantes na alimentação do homem e em especial das aves. Por outro lado, vários autores (MELLO FILHO, 1985; RIBEIRO et al., 1992; MILANO, 1996) não recomendam o plantio dessas espécies por poderem causar danos à saúde humana pelo consumo dos frutos imaturos ou por provocarem sujeira nas ruas ou acidentes com os frutos grandes e carnosos. As espécies Maytenus robusta, Feijoa selowiana, Ardisia ambigua, Ardisia solanacea e Tocoyena bullata, apesar de apresentarem frutos carnosos, não chegam a causar os problemas citados acima, por não produzirem grandes quantidades de frutos. 
É evidente que estudos morfológicos e fenológicos são imprescindíveis mas não suficientes para se eleger as espécies ideais para a arborização. Há a necessidade de se obter informações sobre a disponibilidade de propágulos, a germinação, o transplante, a condução da muda, o pegamento em local definitivo, o sistema radicular, o aceite de podas, a toxicidade, a nutrição e a resistência a pragas e doenças.

\section{CONCLUSÃO}

As espécies arbóreas de pequeno porte e os arbustos que mais se aproximaram ao padrão desejado para a arborização viária são: Tabernaemontana elegans, Senna cana, Lonchocarpus filipes, Calliandra hematocephala, Malvaviscus mollis, Feijoa selowiana, Almeidea caerulea, Esenbeckia grandiflora e Metternichia princeps. E em relação às árvores são Thevetia thevetioides, Ardisia ambigua, Ardisia solanacea, Tabebuia roseo-alba, Cordia sebestena, Kielmeyera excelsa, Senna multijuga, Saraca indica, Eugenia brasiliensis, Eugenia multicostata e Tocoyena bullata.

\section{AGRADECIMENTOS}

Agradecemos a dedicação de Antonio Geremias, que, com seus conhecimentos, contribuiu para a realização deste trabalho.

\section{REFERÊNCIAS BIBLIOGRÁFICAS}

ALENCAR, J.C. Interpretação fenológica de espécies lenhosas de Campinas na Reserva Biológica de Campina do INPA ao Norte de Manaus. Acta Amazônica, v. 20, n.1, p. 145-183, 1990.

ALENCAR, J.C. Fenologia de cinco espécies arbóreas tropicais de Sapotaceae correlacionada a variáveis climáticas na reserva Ducke, Manaus. Acta Amazônica, v. 24, p. 161-182. 1994.

BENCKE, C.S.C. \& MORELLATO, L.P.C. Estudo comparativo da fenologia de nove espécies arbóreas em três tipos de floresta atlântica no sudeste do Brasil. Revista Brasileira de Botânica, v. 25, n. 2, p. 237-248, 2002a.

BENCKE, C.S.C. \& MORELLATO, L.P.C. Comparação de dois métodos de avaliação da fenologia de plantas, sua interpretação e representação. Revista Brasileira de Botânica, v. 25, n. 3, p. 269-275, 2002 b.

BIONDI, D. Tratamentos silviculturais em árvores de ruas. In: ENCONTRO NACIONAL SOBRE ARBORIZAÇÃO URBANA, 2, Maringá, 1987. Anais... Maringá, Prefeitura Municipal de Maringá, 1987. p.43-47.

BIONDI, D. Solo urbano e nutrição de árvores: estudo do caso Curitiba-PR. In: ENCONTRO NACIONAL SOBRE ARBORIZAÇÃO URBANA, 6, Salvador, 1996. Anais... Salvador, Prefeitura Municipal de Salvador, 1996. p.12-18.
COMPANHIA ENERGÉTICA DE SÃO PAULO. Guia de arborização. 3 ed. São Paulo: CESP, 1988. 33p. (Coleção Ecossistemas Terrestres, 006).

d'EÇA-NEVES, F.F. \& MORELLATO, L.P.C. Métodos de amostragem e avaliação utilizados em estudos fenológicos de florestas tropicais. Acta Botanica Brasilica, São Paulo, v. 18, n. 1, p. 99-108, 2004.

FERRAZ, D.K.; ARTES, R.; MANTOVANI, W. \& MAGALHÃES, L.M. Fenologia de árvores em fragmento de mata em São Paulo, SP. Revista Brasileira de Biologia, v. 59, n. 2, p. 305-317, 1999.

FISCHER, G.R. Características positivas de espécies indicadas para arborização pública. In: ENCONTRO NACIONAL SOBRE ARBORIZAÇÃO URBANA, 1, Porto alegre, 1985. Anais... Porto Alegre, Prefeitura Municipal de Porto Alegre/ Secretaria Municipal do Meio ambiente, 1985. p.129-149.

FRANKIE, G.W., BAKER, H. \& OPLER, P.A. Comparative phenological studies of trees in tropical wet and dry forest in the lowlands of Costa Rica. Journal of Ecology, v.62, p.881-919, 1974.

FUNCH, L.S.; FUNCH, R. \& BARROSO, G.M. Phenology of gallery and montane forest in the Chapada Diamantina, Bahia, Brazil. Biotropica, v. 19, n. 1, p. 40-50, 2002.

GREY, G.W. Urban foresty. 2. ed. New York: John Wiley \& Sons, 1996. 156p.

GRIZ, L.M.S. \& MACHADO, I.C.S. Fruting phenology and seed dispersal syndromes in caatinga, a tropical dry forest in the northeast of Brazil. Journal of Tropical Ecology, v. 17, p. 303-321, 2001.

HALLÉ, F.; OLDMAN, R.A.A. \& TONLINSOM, P.B. Tropical trees and forest: an architectural analysis. Berlin: Springer Verlag, 1978.

HICKEY, M.\& KING, C. The Cambridge Illustrated Glossary of Botanical Terms. Cambridge: Cambridge University Press, 2000. 208p.

IRGANG, B. Aspectos botânicos e espécies utilizadas na arborização urbana. In: ENCONTRO NACIONAL SOBRE ARBORIZAÇÃO URBANA, 1., Porto Alegre, 1985. Anais... Porto Alegre, Secretaria do Meio Ambiente, 1985. p. 57-61.

KELLER, R. Neglected vegetative characters in field identification at the supraspecific level in woody plants: phyllotaxy, serial buds, syllepsis and architecture. Bot. Joun. Linn. Soc., v. 116, p.33-51, 1994.

KÖPPEN, W. Climatologia: com un estudio de los climas de la tierra. México: Fondo de Cultura Económica. 1948.

LIMA, A. M. L. P. Piracicaba/SP: análise da arborização viária na área central e em seu entorno. Piracicaba: ESALQ/USP, 1993. 283 p. Doutorado (Solos e Nutrição de Plantas).

MACHADO. I.C.S.; BARROS, L.M. \& SAMPAIO, E.V.S.B. Phenology of caatinga species at Serra Talhada, PE, northeastern Brazil. Biotropica, v. 29, n.1, p. 57-68, 1997. 
MATTHES, L.A.F. Composição florística, estrutura e fenologia de uma mata residual do planalto paulista: Bosque dos Jequitibás (Campinas, SP.). Campinas: Instituto de Biologia, UNICAMP, 1980. 209p. Dissertação (Mestrado em Ecologia)

MELLO FILHO, L. E. Arborização urbana. In: ENCONTRO NACIONAL SOBRE ARBORIZAÇÃO URBANA, 1., Porto Alegre, 1985. Anais... Porto Alegre, Prefeitura Municipal de Porto Alegre/Secretaria Municipal do Meio ambiente, 1985. p.117-127.

MIKICH, S.B. \& SILVA, S.M. Composição florística e fenologia das espécies zoocóricas de remanescentes de floresta estacional semidecidual no centro0oeste do Paraná, Brasil. Acta Botanica Brasilica, v. 15, n. 1, p. 89-113, 2001.

MILANO, M.S. Arborização urbana no Brasil: mitos e realidade. In: ENCONTRO NACIONAL SOBRE ARBORIZAÇÃO URBANA, 6., Salvador, 1996. Anais... Salvador, Prefeitura Municipal de Salvador, 1996. p.12-18.

MORELLATO, L.P.C.; RODRIGUES, R.R.; LEITÃO FILHO, H.F. \& JOLY, C. A. Estudo comparativo da fenologia de espécies arbóreas de floresta de altitude e floresta mesófila semi-decídua na Serra do Japi, Jundiaí, São Paulo. Revista Brasileira de Botânica, v. 12, p. 85-98, 1989.

MORELLATO, L.P.C.; RODRIGUES, R.R.; LEITÃO FILHO, H.F. \& JOLY, C.A. Estratégias fenológicas de espécies arbóreas em floresta de altitude na Serra do Japi, Jundiaí, São Paulo. Revista Brasileira de Biologia, v. 50, n. 1, p. 149-162, 1990.

MORELLATO, L.P.C. \& LEITÃO FILHO, H.F. Estratégias fenológicas de espécies arbóreas em floresta mesófila na Serra do Japi, Jundiaí, São Paulo. Revista Brasileira de Biologia, v. 50, n.1, p. 163-173, 1990.

MORELLATO, L.P.C.; TALORA, D.C.; TAKAHASI, A.; BENCKE, C.S.C.; ROMERA, E.C. \& ZIPARRO, V. Phenology of atlantic rain forest trees: a comparative study. Biotropica, v. 32, n. 4b, p. 811-823, 2000.

NUNES, M.L. Caracterização e avaliação da arborização de ruas de Cascavel - Paraná. In: ENCONTRO NACIONAL SOBRE ARBORIZAÇÃO URBANA, 6., Salvador, 1996. Anais... Salvador, Prefeitura Municipal de Salvador, 1996. p.21-32.

ORTOLANI, A. A. ; PINTO, H.S.; PEREIRA, A. R. \& ALFONSI, R.R. Parâmetros climáticos e a cafeicultura. Campinas: Instituto Brasileiro de Café, 1970. 27p.

PALERMO JUNIOR, A. Planejamento da arborização urbana visando a eletrificação e as redes de distribuição. In: ENCON-
TRO NACIONAL SOBRE ARBORIZAÇÃO URBANA, 2., Maringá, 1987. Anais... Maringá, Prefeitura Municipal de Maringá, 1987. p.68-79.

RIBEIRO, M. A. et al. Programa de arborização de Belo Horizonte - Projeto verde-vivo. In: ENCONTRO NACIONAL SOBRE ARBORIZAÇÃO URBANA, 4., Vitória, 1992. Anais... Vitória, Prefeitura Municipal de Vitória, 1992. p.161-174.

SANCHOTENE, M.C.C. Frutíferas nativas úteis à fauna na arborização urbana. In: ENCONTRO NACIONAL SOBREARBORIZAÇÃO URBANA, 1., Porto Alegre, 1985. Anais... Porto Alegre, Prefeitura Municipal de Porto Alegre/ Secretaria Municipal do Meio Ambiente, 1985. p.105 - 111.

SANCHOTENE, M.C.C. Situação das áreas verdes e da arborização urbana em Porto Alegre. In: ENCONTRO NACIONAL SOBRE ARBORIZAÇÃ̃O URBANA, 3., Curitiba, 1990. Anais... Curitiba, FUPEF, 1990. p.34-40.

SANTIAGO, A.C. Arborização de cidades. 4.ed. Campinas: CATI, 1980. 24p. (Boletim Técnico, 90).

SANTIAGO, D.V.R. Controle fitossanitário em arborização urbana. In: ENCONTRO NACIONAL SOBREARBORIZAÇÃO URBANA, 3., Curitiba, 1990. Anais... Curitiba, FUPEF, 1990. p.101-114.

SEITZ,R.A. Considerações sobre a poda de árvores na arborização urbana. In: ENCONTRO NACIONAL SOBRE ARBORIZAÇÃO URBANA, 3., Curitiba, 1990. Anais.. Curitiba, FUPEF, 1990. p.87-100.

SOARES, M. P. Verdes urbanos e rurais: orientações para arborização de cidades e sítios campesinos. Porto Alegre: Cinco Continentes. 1998. 242p.

SOUZA, H.M. Arborização de ruas. O Agronômico, Campinas, v.21, p. 109-134, 1973.

SOUZA, H.M. Algumas espécies nativas para arborização de vias públicas. In: ENCONTRO NACIONAL SOBRE ARBORIZAÇÃO URBANA, 5., São Luís, 1994. Anais... São Luís, 1994. p.66-74.

STRASBURGER, E., et al. Tratado de Botánica. 7. Ed. Barcelona: Ed. Omega S.A., 1988. 1098p.

TALORA, D.C. \& MORELLATO, L.P.C. Fenologia de espécies arbóreas em floresta de planície litorânea do sudeste do Brasil. Revista Brasileira de Botânica, v. 23, n. 1, p. 13-26, 2000.

WINTERS, G.H.M. Curso avançado de paisagismo. Campinas: Centro Paisagístico Gustaaf Winters, 1991. 109p. (Apostila) 